\title{
What can be learned from the devastating death of Jack Adcock
}

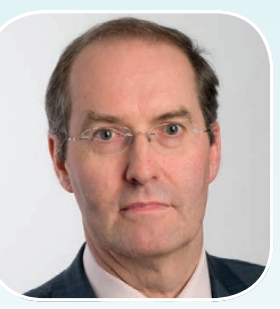

\author{
While the case of six year-old Jack Adcock relates to a hospital \\ medical ward, there are still learning points for the dental \\ profession, says Stephen Henderson, a dental adviser at MDDUS
}

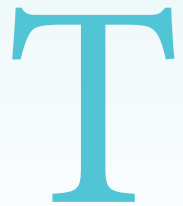

he sad story of Jack Adcock and Dr Hadiza Bawa-Garba has been widely reported in the national media. In summary, a six-yearold boy with a complex medical history was admitted to hospital dehydrated and unresponsive. He died later the same day after a series of errors, some made by individuals and others occurred as a result of the system the medical and nursing staff were working in. For example, the computer system for blood results was not working, delaying vital markers for illness from reaching the doctors.

Jack had been suffering from pneumonia which evolved into sepsis and this was not identified correctly. Sepsis progresses very quickly in a child. Dr Bawa-Garba and nurse Amaro were subsequently convicted of manslaughter by gross negligence. Nurse Amaro was erased by the Nursing and Midwifery Council and Dr Bawa-Garba was first suspended by the GMC and then struck off.

However, in August of this year, the High Court's decision to erase Dr Bawa-Garba was overturned in the Court of Appeal and the original sanction of a one year suspension was restored. This happened after medics launched a crowd-funding initiative to pay for Dr BawaGarba’s legal fees.

What emerged from the Court of Appeal judgment is that criminal proceedings and the Professional Conduct Committee are "different bodies with different functions making different decisions and different times". It does not automatically follow that a serious criminal conviction will result in erasure.

While the circumstances in dental practice are highly unlikely to mirror the problems that Dr Bawa-Garba, nurse Amaro and Jack Adcock faced, some lessons can be learned from the sad circumstances.

Patients can present for urgent care with a dental abscess that is potentially life threatening because the airway is at risk and as a result the patient may develop sepsis. The whole team needs to be aware of these risks and have a plan for managing the patient, from the first phone call or walk-in.

Systems should be in place for a rapid assessment and referral to hospital. The assessment should include baseline medical observations, pulse, temperature and possibly blood pressure. Similarly, when faced with acute dental trauma cases, a plan for rapid assessment and management should be actioned. Each member of the team has a role in both types of case, even if that is simply documenting the notes and comforting the relatives.

The nearest to the Dr Bawa-Garba situation is an acute medical emergency in the dental surgery. The dental team often has the advantage of an up-to-date medical history and list of medications, but that may not always be the case, especially if the unknown companion of the patient collapses in the waiting room.

A well-rehearsed drill should follow, with a scribe capturing the times and key steps taken, liaising with the ambulance service to ensure a safe transfer to secondary care. Imagine that a new team member was the only other person present when the patient collapsed in front of you and they didn't know where the oxygen and emergency drugs were kept, nor the exact address of the practice to tell the 999 operator. . whilst it might not amount to manslaughter by gross negligence, HM Coroner and the relatives would be asking some searching questions in the subsequent investigation.
What steps can an inexperienced member of any team do to protect themselves, and their patients from a disaster as outlined in the examples above? First and foremost, speak up. No-one should be treated badly for saying "I don't know" or "help, what should I do?" Team leaders and senior members of the team should ensure that in any given situation no-one is expected to be operating outside their level of competence.

Medical emergency care should be practised with the whole team, including non-clinical members so that everyone has a basic competence in life support techniques. Life-long learning is crucial, but it has to start somewhere and no-one has specialist skills on their first day in the job.

Those who ask for help seem to learn quicker than those who silently watch on. A confident leader is a leader who is present and welcomes challenge and debate from their teams.

MDDUS (The Medical and Dental

Defence Union of Scotland) is

a medical and dental defence organisation providing access to professional indemnity and expert medico- and dento-legal advice for doctors, dentists, dental therapists and dental hygienists and other healthcare professionals throughout the UK.

For further information on MDDUS, go to www.mddus.com. 